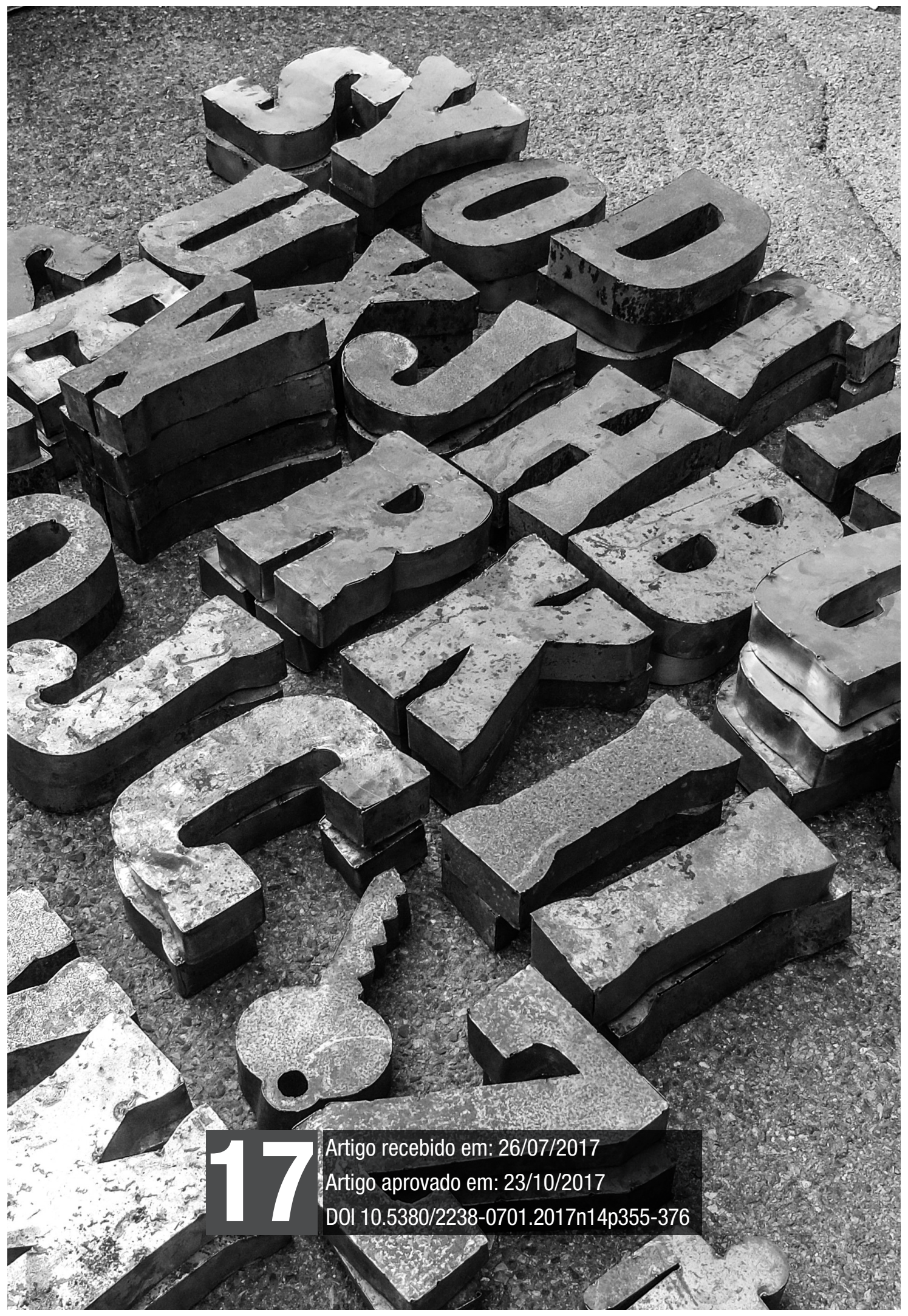


Linguagem. Mídia. Trabalho. Dialogismo. 


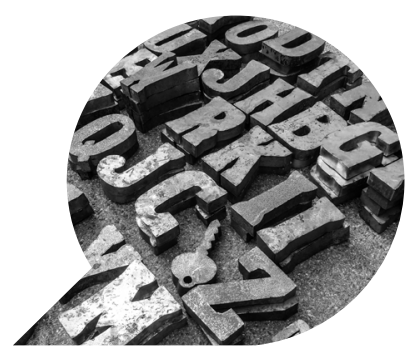

\title{
Trabalho e mídia: construções discursivas sobre o universo do trabalho no Brasil em conteúdos jornalísticos
}

\author{
Work and the media: discursive constructions about the \\ universe of work in Brazil in journalistic contents
}

Trabajo y medios de comunicación: construcciones discursivas sobre el universo del trabajo en Brasil en contenidos periodísticos

ERIKE LUIZ VIEIRA FEITOSA*

ANGELA MARIA RUBEL FANINI**

Resumo: Com base em conceitos e princípios do pensamento bakhtiniano e do Círculo russo, este artigo analisa construções discursivas a respeito do trabalho e do trabalhador em editoriais de veículos de comunicação que versam sobre uma suposta improdutividade do brasileiro e também em reportagens sobre pessoas em situações de trabalho degradantes. Nos dois cenários analisados, demonstra-se que o trabalho assume relevância central, mas fica sujeito à racionalidade do crescimento econômico uni-

\footnotetext{
* Mestre em Tecnologia e doutorando em Tecnologia e Sociedade pela Universidade Tecnológica Federal do Paraná (PPGTE/UTFPR). É graduado em Comunicação Social - Jornalismo (UFPR) e especialista em Comunicação Empresarial e Institucional (UTFPR). Atualmente é jornalista do Instituto Federal do Paraná (IFPR) e membro do grupo de pesquisa "Discursos sobre Tecnologia, Trabalho e Identidades Nacionais" (PPGTE). Email: erik.feitosa@ifpr.edu.br.

** Doutora em Teoria Literária e Literatura Brasileira pela Universidade Federal de Santa Catarina (UFSC). Docente da UTFPR - Programa de Pós-Graduação em Tecnologia e Sociedade (PPGTE) e do Centro Universitário Campos de Andrade (Uniandrade). Bolsista de produtividade em pesquisa do CNPq. Email: rubel@utfpr.edu.br.
} 
direcional, submisso ao capital. Já o trabalhador, peça substituível de uma engrenagem que não pode parar, é percebido como algo do qual se precisa extrair a cada dia mais rendimentos ou alguém que, pontualmente, precisa ser defendido de um sistema que, de forma contraditória, pressupõe intensificação laboral e condições mínimas de trabalho.

Palavras-chave: Linguagem; Trabalho; Mídia e trabalho; Trabalhador; Dialogismo.

Abstract: Based on concepts and principles of Bakhtinian and the Russian circle thought, this article analyzes discursive constructions regarding work and the worker in editorials of vehicles of communication that talk about a supposed unproductiveness of the Brazilian and also in reports about people in degrading work situations. In the two scenarios analyzed, it is shown that the work assumes central relevance, but is subject to the rationality of unidirectional economic growth, submissive to capital. On the other hand, the worker, a substitutable part of a gear that can not stop, is perceived as something that needs to be extracted every day more income and someone who, on time, needs to be defended from a system that, in a contradictory way, presupposes labor intensification and minimum working conditions.

Key-words: Language; Work; Media and work; Worker; Dialogism.

Resumen: Con base en conceptos y principios del pensamiento bakhtiniano, este artículo analiza construcciones discursivas acerca del trabajo y del trabajador en editoriales de vehículos de comunicación que versan sobre una supuesta improductividad del brasileño y también en reportajes sobre personas en situaciones de trabajo degradantes. En los dos escenarios analizados, se demuestra que el trabajo asume relevancia central, pero queda sujeto a la racionalidad del crecimiento económico unidireccional, sumiso al capital. Mientras tanto, el trabajador, pieza sustituible de un engranaje que no puede parar, es percibido como algo del que se necesita extraer cada día más rendimientos o alguien que, puntualmente, necesita ser defendido de un sistema que, de forma contradictoria, presupone la intensificación laboral y condiciones mínimas de trabajo.

Palavras clave: Palabras clave: Lenguaje; Trabajo; Medios y trabajo; Trabajador; Dialogismo. 


\section{Introdução}

Este artigo destaca duas visões com relevante incidência nos discursos que permeiam conteúdos publicados por jornais, emissoras de TV, revistas e sites do Brasil a respeito do trabalhador. Baseada no estereótipo do brasileiro culturalmente preguiçoso, a primeira diz respeito a um discurso que cobra deste sujeito cada vez mais produtividade. A outra denuncia as precárias condições de vida desse indivíduo nesse mesmo sistema, que se preocupa com os resultados financeiros e despreza os aspectos humanos das relações sociais mediadas pelo trabalho. A partir das duas posições, e com base nos pressupostos teóricos e metodológicos da análise do discurso de viés bakhtiniano, propõe-se uma reflexão sobre os aspectos ambíguos assumidos pelo trabalho no capitalismo contemporâneo, bem como pelo papel desempenhado por jornalistas e empresas de comunicação na atividade de leitura dessas realidades polissêmicas.

A análise se divide em três partes. A primeira apresenta a visão do "trabalhador que precisa ser produtivo" e é desenvolvida a partir de editoriais publicados por jornais brasileiros que versam sobre a improdutividade do trabalhador. A segunda, desenvolvida a partir de séries de reportagens vencedoras de prêmios de jornalismo, diz respeito a construções discursivas que, denunciando a precariedade da vida de trabalhadores em situação de exploração extrema, evidenciam a necessidade de oferta de proteções sociais a esses sujeitos.

O corpus ${ }^{1}$ selecionado permite a reflexão, desenvolvida na última parte, acerca do caráter que o trabalho tem assumido no sistema capitalista e também nas formas como essa temática é retratada pelos meios de comunicação brasileiros.

\footnotetext{
${ }^{1} \mathrm{O}$ corpus foi definido no âmbito das discussões suscitadas por um projeto de pesquisa que busca compreender a mecânica de funcionamento das lentes discursivas dos meios de comunicação brasileiros quando o objeto por eles retratado é o trabalhador. Em um primeiro momento, em nível de mestrado, trabalhou-se com editoriais de jornais e revistas que discutiam a ideia do brasileiro culturalmente preguiçoso. Depois, já em nível de doutorado, passou-se a analisar o mesmo objeto a partir de reportagens vencedoras de prêmios de jornalismo cujo tema central era o trabalho. Com a mudança de gênero discursivo, ficou evidente a existência das duas visões sobre o trabalhador brasileiro analisadas neste artigo.
} 


\section{Abordagem teórico-metodológica}

O pensamento bakhtiniano e do Círculo russo ${ }^{2}$ considera as relações indissolúveis entre língua, linguagens e história (BRAIT, 2014, p. 10). O objeto de estudo de uma análise dialógica do discurso (ADD) não são os textos vistos como sistemas em si, mas os sentidos que adquirem quando são considerados seus aspectos extralinguísticos (BAKHTIN, 2013). Nessa perspectiva, não há categorias dadas a priori que sejam aplicáveis de forma mecânica a textos e discursos. São as relações presentes nos discursos que possibilitam o surgimento de categorias e estratégias analíticas. A ADD lida com o embate entre enunciados, sem, no entanto, prometer conclusões definitivas, absolutas. Admite-se que dos confrontos discursivos não surjam, necessariamente, sínteses obrigatórias, mas que a partir deles é possível observar as posições axiológicas dos interlocutores, os lugares ocupados pelo "eu" e pelo "outro". Não se trata de desvelar sentidos ocultos, como se houvesse algo misticamente escondido no discurso que pudesse ser vislumbrado a partir de uma abordagem ou método já finalizado e antedado, mas de perceber as relações adjacentes a cada enunciado, a cada sequência de enunciados, a cada sujeito do discurso. Dialógicas, essas relações estão presentes no que o sujeito comunica, mas não se limitam ao que está escrito, gravado ou falado. Essa perspectiva leva em conta que a linguagem humana é viva e dinâmica, que a palavra está no campo da vida (VOLOSHINOV, 2011, p. 154). Por isso, o objetivo primário da abordagem dialógica é o embate de vozes que, anseia-se, sejam isônomas e imiscíveis, pois o homem se revela apenas por meio do diálogo, mais precisamente, por meio da comunicação com outrem (BAKHTIN, 2013, p. 293).

Os discursos reproduzidos pelos veículos de comunicação alimentam o que a perspectiva bakhtiniana classifica como ideologia do cotidiano ${ }^{3}$.

\footnotetext{
${ }^{2} \mathrm{Na}$ Rússia do início do século XX, Mikhail Bakhtin e o Círculo russo formaram um grupo de estudiosos, sobretudo da linguagem, que a tratava sob a perspectiva materialista histórica. Entretanto, eles enfatizavam a ontologia da linguagem, e não somente a do trabalho, como é característico no marxismo. Para o Círculo, a linguagem em forma de discurso, ou seja, em reais condições de comunicação entre os sujeitos do diálogo, não deve ser percebida como um sistema de signos autônomos da realidade social ou como algo que o enunciador deve apenas assimilar, como um código (fazendo dela apenas um instrumento). A linguagem é poderosa força social em que os embates axiológicos e as lutas intraclasses e entre classes ocorre. É dinâmica, não neutra e está em processo ininterrupto de disputa social.

${ }^{3}$ Para Bakhtin e o Círculo, a ideologia se consolida não por uma relação verdade-mentira, falso-verdadeiro, tese-antítese, mas pelo embate entre sujeitos diferentes, de classes sociais diversas ou intraclasses, que utilizam e, o tempo todo, dão novos sentidos aos mesmos signos, sendo o principal deles a palavra (BAKHTIN/VOLOSHINOV, 2014). Dessa forma, não há como compreender ideologia como falsa consciência ou simplesmente como a expressão de uma ideia, mas como expressão de uma tomada de posição determinada.
} 
São compostos por enunciados que se referem a aspectos concretos da realidade material e, por isso, criam, recriam ou distorcem essa realidade, refletindo e refratando-a. Reflexão e refração são perspectivas básicas para o Círculo russo, devido à filiação do grupo à tradição materialista histórica. Nesse passo, eles advogam pela ligação da linguagem à realidade, ou seja, a linguagem manifesta a realidade. Os homens nomeiam a realidade para com ela se comunicar e defini-la. A linguagem reflete a realidade. No nosso caso, o trabalhador brasileiro é real, existe no meio social e a linguagem jornalística o define. Entretanto, o Círculo se afasta de uma concepção mecanicista-leninista em que a linguagem é vista, apenas, como um meio técnico de "fotografar" a realidade. A linguagem não é puro reflexo do real, mas o refrata. Por que o refrata? Por ser mediada pelas posições axiológicas dos sujeitos que a emitem, quer falando, quer escrevendo. No caso aqui analisado, entre o trabalhador, ou seja, o objeto a ser discursado, e as palavras sobre ele proferidas, há o mediador desse ato. Quem é esse mediador? O sujeito responsável pelo discurso está vinculado a um periódico, a um partido político, a uma experiência de vida que o leva a discursar de certo modo sobre aquele trabalhador. A linguagem para o Círculo é, simultaneamente, reflexão e refração e é nessa acepção que a empregamos, percebendo que a identidade do trabalhador pode ser dada de modo diverso dependendo da forma como ele é apresentado. Os diferentes discursos sobre o trabalhador estão ancorados em ideologias já cristalizadas, operam a partir delas ou até mesmo as modificam, atualizando-as. Assim, enunciações como as que serão analisadas neste artigo são, também, palavras do cotidiano, possuem articulações e origem definidas, inspiração ideológica, interlocutores reais que as promovem ou desqualificam. Uma análise dialógica do discurso busca compreender essas vozes, propiciando que entrem em embate com outras, no intuito de perceber diferentes sentidos, noções e ideologias que as permeiam, bem como os fatores que os movimentam e os fins aos quais estão a serviço.

Outro conceito fundante para o Círculo é a dialogia. Toda linguagem é dialógica, ou seja, está sempre orientada para responder a algo, quer seja anterior a ela, quer seja antecipando uma réplica. Nenhum ato de fala ou escrita é original, partindo unicamente de quem o emite. Qualquer ato discursivo intenta responder a questões de seu tempo já comentadas por outras vozes. Por exemplo, o trabalhador brasileiro vem sendo falado por muitas vozes ao longo da história. ${ }^{4}$ Quando

${ }^{4}$ No período imperial o trabalho era algo negativo em muitos discursos, visto que era majoritariamente realizado por escravos e esses não eram considerados seres humanos. Na República Velha, os trabalhadores e seus levantes populares, com suas greves, eram considerados caso de polícia por 
o jornalista entra nessa seara, já o encontra como objeto discursivo e a sua voz entrará em dialogia com essas outras, apropriando-se delas, incorporando-as, refutando-as, carnavalizando-as ou reforçando-as. Em nossa análise, vimos que os discursos desabonadores sobre a identidade do trabalhador, caracterizando-o como improdutivo, são, também, mobilizados pelas empresas de mídia. Muitos são os discursos sociais que manifestam o trabalhador brasileiro como alguém ocioso e nesses periódicos estudados, isso é reproduzido. Eis aí um processo de dialogia em que há o reforço de um discurso estereotipado. Ele reaparece com fins claramente depreciativos, afastando-se de uma crítica às condições de trabalho precárias e jogando toda a culpa sobre o trabalhador. Esse discurso é refratário à realidade nacional, em parte, pois não a reflete, uma vez que vemos dia a dia os transportes coletivos transportarem os trabalhadores para espaços de labor, provando que trabalham. Assim, é temerário se criar um discurso de improdutividade, pois este carece de referente, ou seja, precisa de reflexão, nos termos do Círculo russo. Entretanto, esse discurso, como é o caso aqui estudado, é dado somente como refração, pois desconhece a realidade e se institui com, apenas, uma posição axiológica, que é negativa, sobre o trabalhador.

Todo discurso é uma mediação entre o sujeito emissor e os objetos, mas é necessário se verificar quando essa mediação é dada apenas como reforço de vozes estereotipadas que se afastam em completo da realidade. É o que vimos nas vozes que manifestam o mundo do trabalho, reduzindo-o apenas à figura do trabalhador improdutivo. Outra: o discurso aí não toca na questão do desemprego, uma vez que a economia não emprega a todos, forçando milhões à ociosidade. As filas por vagas de emprego são imensas quando se abrem tais oportunidades, evidenciando a vontade obreira do nosso trabalhador, mas o discurso, aí, é, somente, refratário: gira em falso sem a reflexão sugerida pelo Círculo russo. Mesmo assim, o discurso manifesta o trabalhador, recuperando um conjunto discursivo nefasto a ele, contribuindo para criar-lhe uma identidade nada enobrecedora. Toda linguagem é dialógica, mas isso não impede que crie expedientes monológicos a fim de passar e criar uma visão única e fechada sobre o objeto. Por exemplo, os discursos

muitos. Já na Era Vargas esse mesmo trabalhador adquire prestígio e Getúlio Vargas endereça seus discursos a ele também. Em decorrência de seu projeto de industrialização nacional, Vargas precisava qualificar esse trabalhador, a fim de que ele aderisse ao seu projeto. Assim, o trabalhador começa a possuir direitos - e não apenas deveres - e surge, discursivamente, de modo diverso. A respeito dele, há vozes do cotidiano, da literatura, da economia. 
desabonadores sobre os trabalhadores apenas focam na ociosidade e na improdutividade, mas silenciam sobre as condições precárias das escolas que mal qualificam para o trabalho e do próprio mercado, que, por não ser capaz de gerar empregos para todos, alija muitos, mesmo qualificados, de alcançarem uma posição no mundo do trabalho. Esses discursos também silenciam sobre as condições quase escravizantes e de má remuneração da atividade laborativa, o que também leva a uma fuga do trabalho por parte de muitos. O discurso jornalístico, assim como qualquer outro, é sempre dialógico, pois quem o emite não é o ser fundante exclusivo daquela enunciação, visto que mobiliza em sua escrita ou fala outros discursos reais que circulam na sociedade, mas essas enunciações podem ser monológicas, criando uma imagem em que o trabalhador é dado apenas em uma única dimensão. Um discurso menos monológico é o que o jornalismo deve buscar, ou seja, em que se apresente o objeto discursivo a partir de suas contradições sociais, ou seja, o trabalhador se manifesta de modo complexo na realidade, ora fugindo do trabalho, ora o desejando, ora qualificado, ora desqualificado. A economia em recessão, as políticas públicas de emprego, a industrialização precária, a importação de tecnologias obsoletas também impactam o meio laboral. Nem tudo depende só do trabalhador.

O jornalismo deve propiciar um discurso menos monológico e mais reflexivo, abrigando mais vozes e demonstrando as contradições sociais que fazem do trabalhador essa figura ora laudada, ora desqualificada. Dialogia e monologismo ocorrem nos enunciados, pois quando emitimos nossas enunciações, geralmente, desejamos convencer o interlocutor de nossa tese e, muitas vezes, para alcançar tal propósito, construímos enunciados monológicos que pendem a reforçar apenas uma visão sobre o objeto, escamoteando e silenciando outras vozes que "dizem" o objeto de modo diverso de nossa perspectiva axiológica.

\section{O trabalhador que precisa ser produtivo}

Em abril de 2014, em resposta à revista britânica The Economist $(2014)^{5}$, os jornais Folha de S. Paulo (2014) e Gazeta do Povo (2014) publicaram editoriais que versavam sobre uma suposta improdutividade

\footnotetext{
${ }^{5}$ Em reportagem de capa, a publicação estrangeira defende que os trabalhadores brasileiros são "gloriosamente improdutivos" e que, para a economia crescer, eles devem "acordar deste estado de estupor" (THE ECONOMIST, 2014). 0 texto aconselha que o Brasil aceite uma série de medidas neoliberais no campo econômico, como, por exemplo, desregulamentações, liberalização, e privatizações.
} 
do trabalhador brasileiro. O discurso no qual estão baseados constrói a imagem de um sujeito que não gosta de trabalhar e que, portanto, seja por questões estruturais (do país) ou por uma deficiência moral, também não está produzindo a contento e, portanto, deve começar a ser mais produtivo. Nas duas abordagens - que se vinculam a matrizes discursivas que não são isoladas, mas fazem parte de um todo ideológico - as questões relativas ao sujeito que trabalha são desconsideradas. $\mathrm{O}$ aspecto central da vida é monetário: ela se resume à produção contínua, ao crescimento econômico unidirecional, como se só houvesse uma única possibilidade para a humanidade, que é a de, sempre, produzir superávits. Em dialogia, versando sobre a improdutividade do trabalhador, os dois periódicos reforçam o discurso da The Economist. Aí a dialogia entra em consonância com a voz que recupera, sendo essa dialogia positiva mais acentuada na Folha de S. Paulo.

Para a Folha de S. Paulo (Ibid.), influenciada pelo panorama político do momento em que o editorial veio a público, o Brasil, como um todo, também é improdutivo, e não apenas o seu trabalhador. Várias chaves indicam o posicionamento axiológico da publicação. Uma delas é a concordância com o que diz um personagem, trazido por The Economist (2014), que critica o ambiente de negócios brasileiro: "Você começa a perder tempo no momento em que pisa no Brasil" (FOLHA DE S. PAULO, 2014). Enunciados como esse demonstram que o importante é crescer e acumular, não perder tempo, e as condições que acarretam em um ambiente ruim ao crescimento econômico são qualificadas como extremamente negativas ${ }^{6}$. Nesse caso, a voz da Folha apenas reverbera a outra voz, dando crédito ao discurso primeiro, que é reacentuado.

O editorial reforça a opinião da The Economist afirmando que "A chave do atraso, como aponta com exatidão a revista britânica, está na produtividade" (Ibid.). A argumentação é acompanhada por vários índices econômicos, que também não são problematizados, mas apenas usados como reforço argumentativo, numa aparente tentativa de se aproximar a uma linguagem científica, haja vista a utilização de jargões e dados de um campo disciplinar específico. "Indignação, apenas, nada pode contra essas cifras acabrunhadoras. É imperativo convertê-la em brio, algo muito mais produtivo" (Ibid), afirma o editorialista, arrematando a análise que culpabiliza, apenas, o trabalhador pelos resultados

\footnotetext{
${ }^{6}$ Mesmo as que tenham por princípio ou fim a proteção à dignidade humana, como, por exemplo, as leis trabalhistas brasileiras, sempre criticadas pelo discurso neoliberal que inspira este editorial.
} 
ruins da economia ${ }^{7}$. A palavra brio remete à noção de honra, altivez, amor-próprio, bravura. É um vocábulo do universo moral. Nesse sentido, uma pessoa sem brio é alguém despido desses valores. Dessa forma, se há a necessidade de transformar indignação em brio, então o brasileiro não tem brio (ou haveria nele pouco desse nobre sentimento). Conclui-se, assim, que uma dose extra é necessária, ou seja, é preciso que a indignação, reação inútil, seja convertida em algo bom: brio. Com uma única palavra, o trabalhador é rotulado de imoral, como se fosse improdutivo apenas por gosto, pela escolha de uma opção (o ócio) em detrimento de outra (trabalho pesado, produtividade). Nessa linha de raciocínio, toda a culpa pelo subdesenvolvimento do país cai sobre a classe trabalhadora, sendo obliterada completamente a responsabilidade de outros grupos sociais e instituições. Também não entram nessa conta os diversos aspectos socioculturais e infraestruturais que influenciam direta ou indiretamente o panorama econômico. Não há referência a questões como luta de classes e má distribuição de renda, da mesma forma que não são consideradas as formas de organização política e econômica do Brasil, que, historicamente, privilegiam determinados segmentos em detrimento de outros. As ideias que giram em torno do trabalho e do trabalhador são meramente instrumentais. A Folha opta por destacar em seu discurso a questão moral, trazendo para a reportagem discursos de longa duração, acionando um universo moral socialmente construído para definir o trabalhador brasileiro. Novamente, o discurso do periódico entra em dialogia com todo um conjunto enunciativo, vinculado à ordem ético-moral, a fim de propor uma solução para o impasse laboral. Em vez de enfatizar a qualificação técnica precária do trabalhador, vinculando-se a um viés mais técnico e mensurável, aposta em outro conjunto enunciativo do campo da moral.

Perceba-se que o discurso da Folha oscila entre dois campos, ora o mais técnico quando republica o discurso primeiro, reforçando os dados quantificáveis a que nos referíamos, ora o menos técnico e na ordem dos valores morais. São duas vozes conflitantes dentro do enunciado. A Folha parece atualizar o seu discurso com dados da voz do periódico The Economist, mas simultaneamente aposta em outra solução ligada a valores morais, sendo mais tradicionalista. Oscila entre a tradição e

\footnotetext{
${ }^{7}$ Aqui, a Folha entra mais uma vez em dialogia intensa e positiva com a voz que desqualifica o trabalhador. Há um espelhamento dialógico da reportagem primeira, parecendo que a segunda voz é tão somente uma espécie de tradução local do discurso estrangeiro sobre parcela da população brasileira.
} 
a atualização discursiva, apresentando uma bivocalidade discursiva. $\mathrm{O}$ discurso técnico é solapado pelo moral, pois instrumentalizar o trabalhador de um saber técnico é mais rápido, entretanto, esse trabalhador surge como alguém imoral, pois avesso ao trabalho. Nesse caso, a posição axiológica da Folha é bastante pessimista, pois para se alterar valores, vão-se gerações. Nesse caso, o trabalhador brasileiro, mesmo preparado tecnicamente, responde às avessas ao universo laboral. É uma voz monológica, pesada, valorativa e definitiva sobre esse trabalhador. O que predomina é a questão moral e não técnica. O impasse está dado, ou seja, a base infraestrutural da economia formada pelos trabalhadores está determinada de modo fechado pela superestrutura moral, dos valores e ações a eles correlatos. A Folha constrói um discurso em que emerge um a priori moral de difícil solução, mas também de difícil mensuração. Aspectos técnicos são quantificáveis, mas e os morais? Acreditamos que aqui ocorre muito mais refração que reflexão.

Na Gazeta do Povo (2014), a posição editorial é construída de maneira diferente, porém a partir de bases ideológicas semelhantes. Ela não culpabiliza o trabalhador pelos resultados, considerados ruins, da produtividade, criando uma zona de dissidência dialógica. Antes disso, esforça-se para "tentar entender por que afirmações como as da revista The Economist são feitas" (GAZETA DO POVO, 2014). Nesse sentido, são destacados aspectos que dão ou não suporte à produção. Elementos como "baixo capital físico"; "capital humano mediano"; "atraso tecnológico" e "carga tributária pesada" (Ibid.) são alguns dos fatores negativos que determinariam a produtividade do brasileiro. Segundo o jornal, o Brasil conta com apenas um fator positivo, que seria a "abundância de recursos naturais” (GAZETA DO POVO, 2014). Nesse passo, o discurso da Gazeta, embora em diálogo com a voz "primeira", dela se afasta ao enumerar as questões de infraestrutura nas quais o trabalhador está inserido.

Se, por um lado, este editorial é exitoso ao trazer novos elementos à discussão sobre a produtividade, superando a ideia de que os trabalhadores seriam os únicos culpados pela baixa velocidade do crescimento econômico brasileiro, por outro ele também se torna limitado, pois continua operando apenas no interior de categorias do universo econômico, também em uma linha exclusivamente neoliberal. Esse pensamento se incomoda com a ausência de condições ideais para que o capital se reproduza com a velocidade almejada: o fim último das relações humanas é o crescimento econômico, o que importa é a taxa de crescimento 
do capital. Nesse caso, a dialogia é ora truncada, visto que mobiliza outros argumentos, ora ocorre em espelhamento, uma vez que a posição neoliberal é reforçada.

Tanto na Folha de S. Paulo (2014) quanto na Gazeta do Povo (2014), quando se aborda a questão do nível educacional, por exemplo, não se pensa em melhorar a vida das famílias trabalhadoras, mas em aumentar a velocidade e o volume da reprodução do capital. A pessoa que trabalha é tida apenas por esse papel social de agente de produção de riqueza para outrem. É alguém que nasceu para isso e seu compromisso com o trabalho deve ser quase o único foco de sua vida. Porém esse trabalho é exterior a ele, ou seja, é heterônomo, não se ligando à vida do trabalhador, mas ao mercado que dele necessita. $O$ trabalho não ocorre para, também, ser útil em termos ontológicos ao trabalhador, visto que a ótica é somente econômica. Todavia, é moral, como assinalamos, mas este "moral" é ligado ao universo do trabalho e não ao do sujeito. Em nenhum momento se cria um discurso sobre como o trabalhador pode se afeiçoar ao trabalho, construindo, no ambiente laboral, amizades, vínculos, identidade. Ocorre que o trabalhador é peça da engrenagem e não um sujeito laboral dotado de demandas existenciais que vão além do mercado. Não interessam as condições em que trabalha, mas sim se os resultados do seu trabalho são superavitários, se estão contribuindo para o crescimento da economia. Por isso, precisa trabalhar cada vez com mais afinco.

Para além desses dois textos, tal ideia embasa discursos que circulam no noticiário político-econômico brasileiro, refletindo e refratando microrealidades da vida cotidiana, sendo assimilada, naturalizada, inclusive pelas classes trabalhadoras. As pessoas já não se perguntam por que trabalham, como trabalham, em que condições, mas se perguntam se são eficazes e eficientes em termos produtivos para o capital. Há aí uma redução do universo do trabalho, que deveria trazer satisfação, orgulho, identidade, sociabilidade para a classe trabalhadora. Esse discurso somente voltado para o mercado, obliterando as demandas do trabalhador, é poderoso e, reforçado pela mídia, acaba sendo reproduzido em espelhamento dialógico até pelo próprio trabalhador.

\section{O trabalhador que precisa ser defendido}

Reportagens publicadas pelo jornal O Globo em agosto de 2014 denunciaram que produtores de tabaco do Rio Grande do Sul enfrentam 
doenças físicas e psíquicas devido ao contato direto com a folha do fumo (MILHORANCE, 2014a) e que o modelo de produção, totalmente controlado pelas multinacionais fabricantes de cigarros, faz os plantadores se endividarem (MILHORANCE, 2014b) ${ }^{8}$. A ideia central dessas reportagens é mostrar o sofrimento das 180 mil famílias de pequenos agricultores que sustentam a indústria do cigarro em São Lourenço do Sul (RS). Ao contrário do primeiro conjunto de textos aqui analisados, esta série humaniza o trabalhador, transformando-o em personagem de um drama (alguém). Logo de início se percebe que a atividade laboral dessas pessoas é, aparentemente, nociva à saúde, pois traz marcas que são visíveis: "Aproximando-nos, encontramos famílias de agricultores que, em geral, aparentam mais idade do que têm" (MILHORANCE $2014 a$ ). Outros enunciados, como o seguinte, aprofundam essa sensação.

[...] depois de dias intensos de colheita, sofrem enjoo, vômito, dor de cabeça, tremor, fraqueza. 0 que, antes, acreditavam ser o desgaste do trabalho pesado, hoje sabem que é intoxicação por nicotina. Não é só o cigarro, alvo de bem-sucedido cerco nas últimas décadas, que faz mal, mas também o contato da pele do fumicultor com a folha molhada do tabaco [Ibid.].

Segundo a reportagem, a chamada "doença do tabaco verde", já descrita em alguns estudos, ocorre principalmente no período da colheita, quando os agricultores carregam nos braços as folhas úmidas de fumo. Esse contato faz com que o nível de nicotina em seu sangue seja até $700 \%$ maior que o de pessoas fumantes - os dados são da Secretaria de Vigilância em Saúde do Ministério da Saúde. Os efeitos em longo prazo da doença ainda não são conhecidos, mas podem estar relacionados a problemas de saúde como câncer, doença pulmonar obstrutiva crônica e cardiopatias (Ibid).

Os personagens e o ambiente das histórias vão sendo construídos a partir de depoimentos. Em comum, os relatos trazem as marcas do adoecimento, do sofrimento, e um forte sentimento de resignação. $\mathrm{O}$ tom das reportagens é de denúncia. Além da doença, há mortes: a combinação de elevados níveis de nicotina no sangue e agrotóxicos é apontada como uma das principais causas do elevado número de suicídios nas pequenas propriedades onde se cultiva o tabaco (Ibid.). O presidente do

\footnotetext{
${ }^{8}$ Chamada de "Tabaco: um outro lado negro" a série foi vencedora nacional do Prêmio MPT de Jornalismo 2015, na categoria jornal impresso (PRÊMIO MPT DE JORNALISMO, 2015).
} 
sindicato patronal da indústria do Tabaco alega que se os agricultores utilizassem equipamentos específicos de proteção, oferecidos a preço de custo pelas indústrias, a intoxicação não ocorreria. A culpa, para ele, seria do próprio trabalhador, que não teria interesse em se proteger, ideia contestada por estudo desenvolvido na Universidade Federal de Pelotas (RS), que concluiu que "o uso de vestuário de proteção não garantiu efeito contra a doença" e que "depois de terem sido lavadas algumas vezes as roupas perdem a eficácia" (Ibid.). Sobre o equipamento de proteção um agricultor diz o seguinte: "A colheita é no verão, então não tem como aguentar aquela roupa debaixo de sol forte o dia todo. A pressão cai, dá vômito, tontura. Toda vez é a mesma coisa. Mas fazer o quê, se a gente está endividado e tem que se sustentar" (Ibid).

Este tipo de trabalho, para essas pessoas, não é uma questão de escolha. É imposição. Uma vez no ciclo produtivo do fumo, famílias inteiras de pequenos agricultores se tornam dependentes de uma das dez indústrias transnacionais que produzem cigarros ou que enviam folhas de fumo ao exterior. Essas empresas participam de todo o ciclo produtivo, com financiamento de insumos, assistência técnica e compra da safra, o que provoca forte dependência econômica (MILHORANCE, 2014 b). Como a classificação da qualidade da folha é feita pela indústria, muitas vezes longe do campo, o preço final acaba sendo dado pelas multinacionais, que, na prática, determinam o quanto querem pagar. Para o representante patronal, esse modelo garante a competividade do fumo brasileiro, que perde em produção apenas para a China (Ibid.): "Sempre vai ter trabalhador que não produz bem, mas a maioria fica satisfeita". Para completar uma conjuntura muito desfavorável aos agricultores, a reportagem traz dados que evidenciam a cumplicidade das grandes indústrias do fumo com os governos, que incentivam a instalação de fábricas, e também com campanhas eleitorais, evidenciando a articulação das grandes empresas com a classe política.

A repórter não opina explicitamente, mas seu texto se posiciona favoravelmente ao trabalhador, alertando sobre as mazelas de todo um sistema produtivo e sobre a vulnerabilidade do seu elo mais fraco, os pequenos produtores. O subtexto da voz autoral é o de que o trabalhador precisa ser protegido de uma lógica desfavorável a ele 9 .

O mesmo subtexto e uma estratégia discursiva semelhante podem

\footnotetext{
${ }^{9}$ A posição da reportagem desagradou a cadeia produtiva, como comentou a própria repórter após ser premiada pelo trabalho: "Recebi e-mails de diversas associações criticando a matéria, porque na visão delas poderia prejudicar a economia da região." (MILHORANCE, 2014 c).
} 
ser observados na série de reportagens "Viúvas do veneno", 10 publicada pelo jornal Diário do Nordeste em abril de 2013. Um profissional do periódico acompanhou, por sete anos, a luta de trabalhadores rurais contra doenças causadas pela intoxicação por agrotóxicos nas lavouras. Isso lhe deu material para narrar, pela ótica das viúvas, os últimos anos de vida de trabalhadores que perderam a vida em decorrência de doenças causadas pelo contato frequente com agrotóxicos. ${ }^{11}$ A apuração jornalística começou em 2007 quando José Maria Filho, trabalhador rural do município de Limoeiro do Norte (CE), começou a denunciar que o uso indiscriminado de agrotóxicos por fruticultores estava causando doenças na população e nos trabalhadores rurais. Dois anos depois, esta liderança foi assassinada e pesquisadores comprovaram que as suas denúncias faziam sentido.

Uma das histórias, comovente, é a do casal Valderi e Maria. Quando conseguiu emprego em uma grande propriedade produtora de bananas ele foi escalado para o setor de aplicação de agrotóxicos. Trabalhava sem equipamentos de proteção e voltava para casa encharcado de veneno. Nos pés, apenas chinelos. Um dia, com o dedo mínimo do pé necrosado, resolve ir ao médico, que amputa este dedo. Poucos dias depois, um a um, outros dedos são amputados, até que o pé inteiro seja retirado.

Com a mutilação, a perna do ex-trabalhador vive inchada e dolorida. "Eu tô tentando minha aposentadoria, mas, até agora, nada". A empresa em que trabalhou só se pronuncia formalmente para dizer ao Ministério do Trabalho que não tem nenhuma relação com a doença adquirida por seu ex-funcionário (Ibid).

Valderi morre três anos após a primeira amputação, sem ter os direitos trabalhistas assegurados. Em tom literário, o relato jornalístico aprofunda o drama e o sofrimento do casal, da mesma forma que o faz em outras histórias relatadas na série, humanizando a figura da vítima e destacando aspectos subjetivos das relações humanas. A linguagem utilizada demonstra que a pessoa do autor se compadece, envolve-se com a dor alheia, tem empatia pelo outro que lhe conta sobre a dureza da vida trabalhadora.

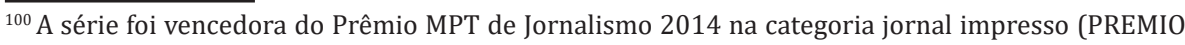
MPT DE JORNALISMO, 2014).

${ }^{11}$ Entre as vítimas também está uma mulher que faleceu durante o período de apuração. Ela lavava as roupas do marido sujas de veneno. Morreu de Leucemia (JÚNIOR, 2013a).
} 
Depois de dias mais sofridos, Valderi amanhece com uma melhora. "Mãinha, vamos visitar Fabim". Fica três dias na casa do amigo. Depois Sousa, João, e assim uma semana de passeio na vizinhança tão próxima, mas distante. Maria só entende que tudo não passa de uma despedida na primeira sexta-feira de volta para casa. Do lado de fora com a irmã, ela ouve a voz do marido. As duas voltaram correndo. Valderi no chão gemendo, se arrastando ao encontro do abraço da mãe-esposa. Sem saber de onde tira força, coloca sozinha o homem na rede, ele pesando o dobro dela. 0 choro abraçado dos dois é a despedida. Valderi não sente mais dor. Só Maria. (Ibid.).

Tristemente verídicas, histórias como essa servem de pano de fundo para que o autor informe sobre o uso de agrotóxicos no Brasil e em como esta prática causa prejuízos à saúde e à dignidade do trabalhador. O país é o maior consumidor mundial de agrotóxicos (JUNIOR, 2013a). Somente no ano de 2011 circularam cerca de US\$ 8,9 bilhões no comércio de veneno, "dominado por nove empresas fabricantes que não concorrem entre si, pois, para cada cultura, uma delas produz um ou vários venenos específicos" (Ibid). Para além da discussão sobre os impactos do uso indiscriminado de veneno na alimentação humana, o resultado dessa utilização, denuncia o repórter, também tem sido o aumento vertiginoso de mortes por intoxicação com agrotóxicos. Somente em 2010 foram registradas 171. No mesmo ano, foram registrados 4789 casos de intoxicação. A realidade, entretanto, deve ser bem mais perversa do que os números indicam, uma vez que mesmo os casos notificados levam muito tempo para chegar ao Sistema Nacional de Informações Toxicológicas: "Os dados que chegam aos centros de toxicologia ainda são precários. A maior parte nem chega. O Ministério da Saúde aponta que, para cada caso de intoxicação registrado, outros 40 não são notificados" (JUNIOR, 2013b).

\section{A ideia de crescimento}

O caso dos fumicultores do sul e dos trabalhadores rurais do nordeste exemplificam algumas das consequências do modelo que exige produtividade a qualquer custo. Quando se prioriza o crescimento econômico, desconsiderando outros aspectos da vida humana, a começar pela dignidade da pessoa que trabalha, um dos resultados é a precarização da vida daqueles que estão na base desse sistema. Como o trabalhador pode ter brio a partir desse trabalho que o inutiliza para a vida? Não 
é difícil imaginar que situações semelhantes ocorram em outros ramos da economia, nos centros urbanos, no setor de serviços, no comércio. Uma gigantesca teia de relações sociais desiguais está posta a serviço da noção de que a economia precisa crescer e que, para isso, os trabalhadores precisam ser cada vez mais produtivos. Os meios de comunicação comerciais, oligopolizados, não estão fora dessa lógica. Pelo contrário, aprofundam-na. Funcionam como arautos desse modelo, que privatiza a riqueza e socializa as mazelas sociais. Até quando criticam os excessos, como a situação dos trabalhadores do sul e do nordeste aqui analisados, contribuem para a sua efetivação, atuando como reguladores do sistema - para que este funcione, há que existir trabalhadores, que não podem ser extintos e nem viver em situação tão precária a ponto de serem impulsionados à revolta.

Autoritárias e elitistas, as duas visões sobre o trabalhador, que não são únicas, mas bastante recorrentes, evidenciam a proposição de Castel (2013, p. 226) de que a riqueza não tem relação direta com o trabalho, mas está vinculada à manutenção de relações de poder desiguais. Trabalho e tecnologia estão cada vez mais aprisionados a essa lógica, como Marx (1975) já denunciava no século XIX ao analisar a introdução da maquinaria no processo produtivo e o aprisionamento do trabalho nas fábricas, processo que, em seu início, abarcava famílias inteiras de proletários. Para ele, o aumento da produtividade no sistema capitalista resulta na obtenção de mais lucros para os detentores do capital e em menor qualidade de vida para os trabalhadores. A estes, reféns de discursos que ora os tratam como coisas e outras vezes destacam a sua vulnerabilidade, resta o trabalho (ou a busca dele), muitas vezes em condições diversas de degradação, seja por condições de exploração extrema ou em decorrência do enfraquecimento das relações sociais no capitalismo de que fala Sennet (2009). À deriva, sem a capacidade de formular uma narrativa para as próprias vidas (Ibid.), as pessoas têm o caráter corroído paulatinamente, estão presas a uma teia de opressões e sofrimento. A angústia maior da contemporaneidade, nesse sentido, seria o isolamento, a individualização, a solidão, a ausência do outro em reinos de individualidades, o enfraquecimento dos laços de solidariedade entre os trabalhadores, que não têm mais lutas comuns, mas são instigados a, cada vez mais, competirem entre si para alcançar um lugar melhor, o que torna as relações sociais cada vez mais líquidas, como aponta Bauman (2008). 
Entretanto, como as duas séries de reportagens aqui analisadas o fizeram, o jornalismo tem a opção de mostrar o trabalhador em seu lado humano, ou seja, dar-lhe, também, um discurso e uma existência, mesmo que duramente impactada pelo trabalho. Quando, nas reportagens, o trabalhador surge como um personagem dentro de um enredo que entrelaça a vida e as suas condições imediatas de sobrevivência, percebemos as contradições do mundo do trabalho. Ao dar voz ao trabalhador, o jornalismo o dota de uma existência plena de significado e ele pode também se posicionar. A vida dos que vivem pela venda da própria força de trabalho gira em torno da própria atividade laboral, que, nesse sentido, é central, porém essa centralidade não pode ser considerada como positivamente ontológica, nos termos dados por Engels (1977) e Lukács (2013), para quem, respectivamente, o trabalho seria o criador do homem ou o responsável pelo salto do ser biológico para o ser social. Pelo contrário, tal qual está configurado, o trabalho no capitalismo contemporâneo está aprisionado, aprisionando, também, o humano, cujas vestes estão encharcadas de fumo, veneno, vergonha, raiva, decepção e desalento.

\section{Considerações finais}

O discurso está inscrito no plano da vida. As palavras, cristalizadas em ideologias, têm o poder de refletir e de refratar determinadas realidades. Sociedades que aceitam a ideia de que é preciso produzir a qualquer custo, de fato, podem começar a fazê-lo. Entretanto, os custos aparecem e é preciso decidir quem paga a fatura, cruz, geralmente, deixada a cargo dos mais fracos. Nesse sentido, é necessário que as reportagens sobre o mundo do trabalho tragam também as vozes dos trabalhadores para o interior discursivo e não somente a voz patronal e a do neoliberalismo. É uma questão de se criar um jornalismo plural, em que a dialogia seja explicitada e não a monologia. Os trabalhadores resistem, têm voz e suas ideias, práticas e pautas estão postas no embate cotidiano que é a vida no capitalismo, mesmo que, em muitas vezes, os meios de comunicação, vinculados a grandes corporações, silenciemnas, construindo ambientes discursivos monológicos em que o embate de vozes se enfraquece.

O autoritarismo, conservadorismo e utilitarismo das duas visões aqui analisadas permitem evidenciar o embate intra e interclasses, que tem barreiras cada vez mais delimitadas. Não se quer mudar a ordem, 
mas mantê-la, mesmo que isso signifique arranjos pontuais, como a defesa de condições mínimas para o trabalho. O jornalismo e os jornalistas contribuem nesse sentido, embarcando na defesa de ideologias dominantes ou denunciando quando há excessos e, com isso, ajudando a fazer pequenos reparos em um todo que é muito maior. Mesmo que necessária, a denúncia, quando há, acaba por ser benéfica ao sistema, pois pleiteia melhorias específicas. Ao mesmo tempo, por meio dessa condução dos embates, enfraquece-se a ideia de que os trabalhadores são, também, agentes da própria emancipação e isso tem força desmobilizadora de transformações sociais. O discurso tem caráter ideológico e se materializa nas práticas socioculturais, interferindo na realidade. Entretanto, como vimos, há um jornalismo que opta por trazer ao palco discursivo o trabalhador que tem uma história diversa sobre as condições laborais. Esse embate, essa disputa, deveria nortear o jornalismo, constituindo-o mais plural e menos monológico.

\section{REFERÊNCIAS}

BAKHTIN, Mikhail. Problemas da Poética de Dostoiévski. 5. ed. Revista. Tradução: Paulo Bezerra. Rio de Janeiro, Forense Universitária, 2013.

; VOLOSHINOV, Valentín. Marxismo e filosofia da linguagem: problemas

fundamentais do método sociológico na ciência da linguagem. 16. ed. Tradução:

Michel Lahud e Yara Frateschi Vieira. São Paulo: Hucitec, 2014.

BAUMAN, Zygmunt. Sociedade individualizada: vidas contadas e histórias vividas. Rio de Janeiro: Zahar, 2008.

BRAIT, Beth. Análise e teoria do discurso. In: BRAIT, Beth. (Org). Bakhtin: outros conceitos-chave. 2. ed. Editora Contexto: São Paulo, 2014, p. 9-31.

CASTEL, Robert. As metamorfoses da questão social: uma crônica do salário. 11. ed. Petrópolis: Vozes, 2013.

ENGELS, Friedrich. O papel do trabalho na transformação do macaco em homem. In: MARX, Karl; ENGELS, Friedrich. Textos. São Paulo: Edições Sociais, 1977. Vol. 1. p. 63-74.

FOLHA DE S. PAULO. Editorial: Brasil improdutivo. Folha de S. Paulo, São Paulo, 22 abr. 2014. Disponível em: <http://www1.folha.uol.com.br/ opiniao/2014/04/1443520-editorial-brasil-improdutivo.shtml>. Acesso em: 06 mai. 2015. 
GAZETA DO POVO. A produtividade do brasileiro. Gazeta do Povo, Curitiba, 21 abr. 2014. Disponível em: <http://www.gazetadopovo.com.br/opiniao/editoriais/aprodutividade-do-brasileiro-9fa658xvbjguj7xyom9qz349a>. Acesso em 27 fev. 2015.

JÚNIOR, Antônio M. a. Viúvas do veneno: Silêncio e dor se multiplicam nos campos brasileiros. Diário do Nordeste, Fortaleza, 17 abr. 2013. Disponível em: $<$ http://diariodonordeste.verdesmares.com.br/cadernos/regional/silencio-e-dorsemultiplicam-nos-campos-brasileiros-1.269133 > . Acesso em: 21 set. 2015.

b. Brasil registra o aumento de mortes por agrotóxicos. Diário do Nordeste, Fortaleza, 17 abr. 2013. Disponível em: <http://diariodonordeste. verdesmares.com.br/cadernos/regional/brasil-registra-o-aumento-de-mortes-poragrotoxicos-1.269139>. Acesso em: 21 set. 2015.

LUKÁCS, György. Os complexos de problemas mais importantes: o trabalho. In: Para uma ontologia do ser social II. 1. Ed. Tradução: Nélio Schneider, Ivo Tonet, Ronaldo Vielmi Fortes. São Paulo: Boitempo, 2013.

MARX, Karl. O capital. Rio de Janeiro: Civilização Brasileira, 1975.

MILHORANCE, Flávia a. Produtores de tabaco enfrentam doenças físicas e psíquicas no RS: Contato com folha do fumo faz nível de nicotina no sangue deles ser até $700 \%$ maior que o de fumantes. O Globo, Rio de Janeiro, 03 ago. 2014. Disponível em: $<$ http://oglobo.globo.com/sociedade/sustentabilidade/produtores-de-tabacoenfrentam-doencas-fisicas-psiquicas-no-rs-13473703\#ixzz48GT3BTVU>. Acesso em: 10 mai. 2016.

b. Modelo de produção controlado pelas fabricantes de cigarros faz plantadores no RS se endividarem: Um produtor que trabalha desde os 7 anos tem débito de R\$ 70 mil. O Globo, Rio de Janeiro, 04 ago. 2014. Disponível em: $<$ http://oglobo.globo.com/sociedade/sustentabilidade/produtores-de-tabacoenfrentam-doencas-fisicas-psiquicas-no-rs-13473703\#ixzz48GT3BTVU>. Acesso em: 10 mai. 2016.

c. Página de vencedores da categoria jornal impresso do Prêmio MPT de Jornalismo: depoimento [ago. 2015]. Disponível em: <http://premiomptdejornalismo. com.br/edicoes_anteriores/edicao-2015/vencedores/impresso.html> Acesso em 12 mai. 2016.

PRÊMIO MPT DE JORNALISMO 2014. Disponível em: <http:// premiomptdejornalismo.com.br/edicoes_anteriores/edicao-2014/vencedores/ impresso.html>. Acesso em 18 mai. 2016. 
PRÊMIO MPT DE JORNALISMO 2015. Disponível em <http:// premiomptdejornalismo.com.br/edicoes_anteriores/edicao-2015/vencedores/ impresso.html> Acesso em 12 mai. 2016.

SENNET, Richard. A corrosão do caráter: consequências pessoais do trabalho no novo capitalismo. Tradução: Marcos Santa Rita. Rio de Janeiro: Record, 2009.

THE ECONOMIST. The 50-year snooze. The Economist, São Paulo, 19 abr. 2014. Disponível em: <http://www.economist.com/news/americas/21600983-brazilianworkers-are-gloriously-unproductive-economy-grow-they-must-snap-out $>$. Acesso em: 18 set. 2014

VOLOSHINOV, Valentin. A palavra na vida e na poesia: introdução ao problema da poética sociológica. In: BAKHTIN, Mikhail. Palavra própria e palavra outra na sintaxe da enunciação. São Carlos: Pedro \& João Editores, 2011. 184p. 